\title{
CO OBSERVATIONS OF HIGH-Z OBJECTS
}

\author{
K. OHTA, K. NAKANISHI, M. AKIYAMA, T.T. TAKEUCHI \\ Dept. of Astronomy, Kyoto Univ., Kyoto 606-01, Japan \\ T. YAMADA, Y. SHIOYA \\ Astronomical Institute, Tohoku Univ., Sendai 980-77, Japan \\ AND \\ K. KOHNO, R. KAWABE, N. KUNO, N. NAKAI \\ Nobeyama Radio Observatory, Nagano 384-13, Japan
}

\section{BR1202-0725 at $\mathrm{z}=4.7$}

We have made a $\mathrm{CO}(\mathrm{J}=2-1)$ observation using the Nobeyama $45 \mathrm{~m}$ telescope aimed at examining physical properties of the molecular gas in the object. Upper limit obtained is $1.8 \mathrm{mK}(3 \sigma)$ at a velocity resolution of $100 \mathrm{~km} \mathrm{~s}^{-1}$, which leads to an upper limit on the molecular gas mass of $5.3 \times 10^{11} M_{\odot}$, if we assume a line width of $250 \mathrm{~km} \mathrm{~s}^{-1}$ obtained in $J=5-4$ line and the Galactic CO-to- $\mathrm{H}_{2}$ conversion factor of $4.5 M_{\odot} \mathrm{K} \mathrm{km} \mathrm{s}^{-1} \mathrm{pc}^{2}$. The line ratio between 2-1 line and 5-4 line as well as those from 7-6 and 43 lines (Omont et al. 1996) imply that the mean gas density is as high as $10^{3-5} \mathrm{~cm}^{-3}$, which is comparable to that in nearby star burst galaxies (e.g., Solomon et al. 1992).

\section{Forming galaxy candidate $\mathrm{cB58}$ at $\mathrm{z}=2.7$}

We have observed the object in $\mathrm{CO}(\mathrm{J}=3-2)$ line aimed at detecting a large amount of molecular gas which is expected from the high star formation rate in this object. We have obtained an upper limit of $7.5 \mathrm{mK}(3 \sigma)$ at a velocity resolution of $25 \mathrm{~km} \mathrm{~s}^{-1}$. The upper limit of the CO luminosity is $4.4 \times 10^{10} \mathrm{~K} \mathrm{~km} \mathrm{~s}^{-1} \mathrm{pc}^{2}$ if we assume a velocity width of $300 \mathrm{~km} \mathrm{~s}^{-1}$. A lower limit on the ratio of the $\mathrm{H} \alpha$ line luminosity to the CO luminosity is at an upper part of, but within the range of ratios for nearby galaxies. Results are presented in Nakanishi et al. PASJ 49, 535 (1997). 